\title{
The effects of diabetes mellitus and hypertension on work productivity
}

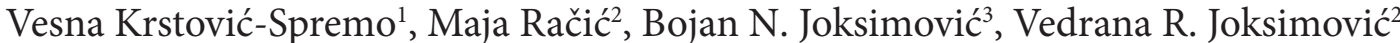

${ }^{1}$ Department of Occupational Medicine Faculty of Medicine, University of East Sarajevo, East Sarajevo, Bosnia and Herzegovina

${ }^{2}$ Family Medicine Department, Faculty of Medicine, University of East Sarajevo East Sarajevo, Bosnia and Herzegovina ${ }^{3}$ Department of Pathological Physiology Faculty of Medicine, University of East Sarajevo, East Sarajevo, Bosnia and Herzegovina

Corresponding author:

Bojan N. Joksimović

Department of Pathological Physiology

University of East Sarajevo

East Sarajevo

Bosnia and Herzegovina

joksimovic_bojan@yahoo.com

Tel.: + 38765373507

Fax.: + 38758210007

Received: 1 July 2014

Accepted: 26 November 2014

Copyright $\odot 2014$ by

Academy of Sciences and Arts

of Bosnia and Herzegovina.

E-mail for permission to publish:

amabih@anubih.ba
Objective. The primary objective of this paper is to examine the impact of diabetes mellitus on the ability to work in patients with diabetes mellitus. The second objective of this paper is to examine the differences in the ability to work between patients with diabetes mellitus and patients with other chronic diseases, such as hypertension. Material and methods. A study was conducted in 10 family medicine practices from two primary health care centers, Pale and East Sarajevo, in the period between July 2009 and May 2010, utilising a retrospective medical records review and a cross sectional survey. The outcomes used to portray respondent's health status included functional measures and ability to work. Functional measures were analyzed using SF-36 and a general questionnaire. Absenteeism and productivity loss were retrospectively analyzed for the past ten years from a regional sick-leave database and the administrative records of the Commission for the assessment of work capacity for the Pension and Disability Insurance Fund of the Republika Srpska respectively. Results. Out of the total number of patients with diabetes, $24.6 \%$ had some form of disability. A statistically significant difference was found between the two groups; patients with diabetes mellitus were much more likely to have problems meeting the required standards at the workplace due to emotional and physical health issues compared to hypertensive patients. Conclusion. Diabetes mellitus appears to reduce an individual's ability to work in comparison to patients with hypertension. There is a need to set up a diabetes mellitus prevention program and to develop and implement effective targeted intervention to help workers to manage their disease better.

Key words: Diabetes mellitus, Work productivity, Disability.

\section{Introduction}

Work is a basic human activity through which every individual realizes their own livelihood. It is closely associated with the categories of health and quality of life. Diabetes mellitus, as a disease with a high prevalence of growth in all countries, threatens to become a global epidemic risk, and thus the question of the ability to work of this category of patients is extremely important in terms of professional orientation, professional selection, work absenteeism and disability evaluation (1).

Lost productivity at work is an important concern for employees, employers, and so- 
ciety. Moreover, the complications related to diabetes mellitus are major cause of disability, reduced quality of life, and death. Employees with diabetes mellitus may stop working prematurely and may experience unemployment, which could translate into a reduction in earned income and savings, and loss of self-esteem. For employers too, lost productivity due to absenteeism, disability and early retirement is an important economic issue (2-9).

Work ability assessment is a continuous process that in ideal social circumstances should accompany a person throughout their entire life. Basically, it has to answer the question of whether there is a match between a man's psychophysical ability and the demands of working conditions and the work environment.

The most common causes of work absenteeism are: disease, occupational disease, and injury at work, injury outside of work, care for a family member or some other reason provided by law (10). According to estimates by the International Labour Organization (ILO) for sick leave, about $5 \%$ of the total employed labour force is absent from work every day. The average number of sick days per employee in the EU was 4.6 days per year (11).

Diabetes mellitus is a common cause of absenteeism in the population. An estimated 171 million people were suffering from diabetes mellitus in 2000, and this number could total 366 million by 2030 (12). Type 2 diabetes mellitus accounts for more than $90 \%$ of all diabetes cases, and it often appears in middle age. In 2010, the prevalence of diabetes mellitus in the U.S. was 11.3 and $26.9 \%$ among individuals aged 20 years or over and 65 years or older, respectively (13). Data provided by the Public Health Institute of Republika Srpska show that the prevalence of diabetes mellitus is $42 \%$ and for hypertension it was $14 \%$ for 2012, in Republika Srpska, Bosnia and Herzegovina (14).
The primary objective of this paper is to examine the impact of diabetes mellitus on the ability to work of people with diabetes. The second objective of this paper is to examine the differences in the ability to work between patients with diabetes mellitus and patients with another chronic disease, such as hypertension. These two chronic diseases were chosen because of their high prevalence in the community and similar hazard effect on the cardiovascular system and overall health.

\section{Materials and methods}

This study was conducted in 10 family medicine practices from two primary health care centers, Pale and East Sarajevo, in the period between July 2009 and May 2010, utilising a retrospective records review and a cross sectional survey.

The sample size for the population of 2326 patients with diabetes mellitus included in the regional Diabetes Registry, with a confidence interval of $6.63 \%$ and a confidence level of $95 \%$, was calculated to be 200 . A specially established audit team randomly selected the medical files of 200 patients with diabetes mellitus from the Diabetes Registry administered by all ten family medicine teams' databases. Patients were registered as patients with diabetes mellitus if they had two fasting plasma glucose levels above 7.8 $\mathrm{mmol} / \mathrm{l}$ or two random plasma glucose levels above $11.1 \mathrm{mmol} / \mathrm{l}$. and/or were treated with insulin and/or oral hypoglycemic agents. Then, the team randomly selected medical files of 200 patients with arterial hypertension from the Hypertension Registry administered by the same family medicine team database. Patients were registered as patients with arterial hypertension if they had blood pressure $\geq 140 / 90$ and/or were treated with antihypertensive agents. Exclusion criteria for the patients with diabetes were the presence of other chronic diseases 
such as associated hypertension, established cardiovascular disease, renal failure, obesity, pulmonary diseases and being unavailable to complete the questionnaire. Exclusion criteria for patients with hypertension were presence of other chronic diseases such as associated diabetes mellitus, established cardiovascular diseases, renal failure, obesity, pulmonary diseases and being unavailable to complete the questionnaire.

All respondents who were included in the study were invited to see their family physician at the scheduled time. During their visit to the family physician, respondents were informed about the aim of the study and their written informed consent was sought and obtained. The outcomes used to portray the respondent's health status included functional measures and the ability to work.

Functional measures of the respondents' health status were assessed during the visit. The respondents were asked to complete two questionnaires. A standardized questionnaire was used to collect current data regarding the respondents' characteristics such as sex, age, place of residence, marital status, education, occupation, duration of diabetes mellitus and hypertension, respondents' perception of their own ability to work and their quality of life. In evaluating the impact of diabetes mellitus and hypertension on respondents, a generic instrument, the selfadministered, linguistically validated Medical Outcomes Study Short Form-36 Health Survey (SF-36) was used. SF-36 is the most widely used generic instrument to quantify health-related problems. It is composed of 36 questions and standardised response choices, and is organised into eight multi item scales: physical function (PF - 10 items); role physical, referring to limitations in performing important life roles due to physical health (RP -4 items); bodily pain (BP - 2 items); general health perceptions $(\mathrm{GH}-5$ items); vitality (VT - 4 items); social functioning (SF-2 items); role emotional, refer- ring to limitations in performing important life roles due to emotional problems (RE - 3 items) and mental health, referring to the absence of anxiety and depression ( $\mathrm{MH}-$ 5 items). All scale scores are linearly converted to a 0-100 scale, with higher scores indicating a better health-related quality of life (HRQoL). Extensive background information on SF-36, as well as standard scoring algorithms and interpretations guides, are available elsewhere $(15,16)$. We used the cross-culturally validated Serbian version of SF-36. The reliability of SF-36, as measured by Cronbach's alpha coefficient was 0.78 . SF-36 mean scores were calculated for both groups (17).

The second outcome was the ability to work. It included absenteeism and productivity loss. The data about absenteeism was retrospectively analyzed reviewing the patients' medical records and regional sickleave database for past ten years. Productivity loss was also retrospectively analyzed using administrative records of the Commission for the assessment of work capacity for the Pension and Disability Insurance Fund of the Republika Srpska for the past ten years.

\section{Ethical statement}

The obtained data were compared between patients with diabetes and patients with hypertension. In the analytical database, personal identifiers were removed to preserve confidentiality, and access to the database was controlled by the Committee for Science and Research of the Medical Faculty Foča, University of East Sarajevo. The study was conducted in accordance with the World Medical Association Declaration of Helsinki of 1975 , as revised in 1983, with the approval of the Ethical Committee of the Medical Faculty of Foča, University of East Sarajevo 


\section{Statistical analyses}

Statistical analyses were carried out using SPSS 17.0 (SPSS Inc., Chicago, IL, USA). Means and standard deviations (SD) for continuous variables and frequency and percentages for categorical variables were used to describe data. The mean scores of SF-36 were calculated for the different groups and the normality of their distributions was tested by the Kolmogorov-Smirnov test. Differences between groups means were analyzed by one way analysis of variance (ANOVA). To compare the difference in answers on their own ability perception between the patients with diabetes mellitus and patients with hypertension, we used a Chi-square statistical test. The correlation between SF-36 and the ability to work were analyzed with Spearman's rho (q) correlation coefficient. Multivariable analysis using linear regression was performed to identify independent factors for the social functioning domain of health related quality of life. The data were presented in tables, and a $\mathrm{p}$-value $<0.05$ was considered to be statistically significant.

\section{Results}

The study included the medical files of 191 adult patients with diabetes mellitus and 100 patients with hypertension. Nine patients with diabetes mellitus and 100 patients with hypertension were excluded from the study due to the presence of associated chronic disease.

The patients in both groups were mainly of male gender, $63.4 \%$ in the diabetes mellitus group and $53 \%$ in the hypertension group, respectively. The average age of the patients with diabetes mellitus was 55.08 years, with a range from 25 to 78 years. The average age of patients with hypertension was 54.9 years, with range from 35 to 65 years. The majority of the patients in both groups were town dwellers. About $86 \%$ of the patients with diabetes mellitus and $75 \%$ of hypertensive patients had either a university or high school degree and a significantly higher proportion of them were employed in blue-collar than white-collar jobs. Approximately, $36 \%$ of patients had had diabetes mellitus from 2 to 5 years, while the majority of hypertensive patients had had the disease for 5 years or longer (Table 1).

Forty patients (21\%) with diabetes mellitus were employed at the time of research, as well as $56(56 \%)$ patients with hypertension $(\chi 2=31.22, p<0.001)$. However, it was found that the number of retirees was higher in diabetes mellitus group (46.6\%). Of those patients who were retired, 53\% were receiving disability pensions due to diabetes mellitus, and $47 \%$ had retired due to their age. In the hypertension group $19 \%$ of patients were receiving old-age pension and none due to disability (Table 1). Fifty-three per cent of patients used oral anti-diabetics while $47.6 \%$ used insulin. Patients with diabetes mellitus felt significantly more disabled than patients with hypertension $(\chi 2=13.46, \quad \mathrm{p}<0.001)$ (Figure 1).

A statistically significant difference between two groups was found in exposure to occupational hazards. The total number of patients with diabetes mellitus exposed to some type of hazard at their work place was 28 . The largest number of patients were exposed to a physical hazard (57.1\%), followed by chemical (28.6\%) and biological hazard $(14.3 \%)$. In the group of patients with hypertension, 20 patients were exposed to some sort of occupational hazard (Table 2).

Out of the total number of patients with diabetes mellitus, $24.6 \%$ had some kind of productivity loss. This group of patients was divided into two subgroups. One subgroup was composed of $13(6.8 \%)$ patients who completely lost the ability to work and the other subgroup of $34(17.8 \%)$ patients who partially lost their ability to work. The patients from both groups took (early) disability retirement (Table 2 ). In the group of pa- 
Acta Medica Academica 2014;43:122-133

Table 1 Characteristics of the patients with hypertension and diabetes mellitus $(n=291)$

\begin{tabular}{|c|c|c|}
\hline \multirow{2}{*}{ Characteristic } & \multicolumn{2}{|l|}{ Patients } \\
\hline & $\mathrm{DM}(\mathrm{n} ; \%)$ & $\mathrm{HT}(\mathrm{n} ; \%)$ \\
\hline \multicolumn{3}{|l|}{ Gender } \\
\hline Female & $70(36.6)$ & $47(47.0)$ \\
\hline Male & $121(63.4)$ & $53(53.0)$ \\
\hline \multicolumn{3}{|l|}{ Age (years) } \\
\hline 20 to 29 & $1(0.5)$ & $0(0.0)$ \\
\hline 30 to 39 & $8(4.2)$ & $2(2.0)$ \\
\hline 40 to 49 & $28(14.7)$ & $24(24.0)$ \\
\hline 50 to 59 & $93(48.7)$ & $48(48.0)$ \\
\hline 60 to 69 & $57(29.8)$ & $30(30.0)$ \\
\hline 70 to 79 & $4(2.1)$ & $0(0.0)$ \\
\hline \multicolumn{3}{|l|}{ Place of living } \\
\hline Town & $123(64.4)$ & $67(67.0)$ \\
\hline Village & $68(35.6)$ & $33(33.0)$ \\
\hline \multicolumn{3}{|l|}{ Marital status } \\
\hline With partner & $134(70.2)$ & $74(74.0)$ \\
\hline Without partner & $57(29.8)$ & $26(26.0)$ \\
\hline \multicolumn{3}{|l|}{ Education } \\
\hline Elementary school & $40(13.7)$ & $25(25.0)$ \\
\hline High school & $131(45.0)$ & $30(30.0)$ \\
\hline University degree & $120(41.2)$ & $45(45.0)$ \\
\hline \multicolumn{3}{|l|}{ Occupation } \\
\hline Blue collar jobs & $20(10.5)$ & $32(32.0)$ \\
\hline White collar jobs & $5(2.6)$ & $14(14.0)$ \\
\hline Farmer & $8(4.1)$ & $7(7.0)$ \\
\hline Retiree & 89 (46.6) & $19(19.0)$ \\
\hline Retiree (due to age) & $42(47)$ & $19(100)$ \\
\hline Retiree (due to disability) & $47(53)$ & $0(0.0)$ \\
\hline Black market job & $7(3.6)$ & $3(3.0)$ \\
\hline Supported by family member & $19(9.9)$ & $9(9.0)$ \\
\hline Unemployed duo to the lack of job & $43(22.7)$ & $16(16.0)$ \\
\hline \multicolumn{3}{|l|}{ Duration of the disease (years) } \\
\hline$<2$ & $57(30.0)$ & $28(28.0)$ \\
\hline 2 to 5 & $70(36.4)$ & $32(32.0)$ \\
\hline$>5$ & $64(33.6)$ & $40(40.0)$ \\
\hline \multicolumn{3}{|l|}{ Smoking } \\
\hline Smoker & $51(26.7)$ & $21(21.0)$ \\
\hline Non smoker & $129(67.5)$ & $75(75.0)$ \\
\hline Ex-smoker & $11(5.8)$ & $4(4.0)$ \\
\hline \multicolumn{3}{|l|}{ Alcohol consumption } \\
\hline Yes & $24(12.6)$ & $19(19.0)$ \\
\hline No & $167(87.4)$ & $81(81.0)$ \\
\hline
\end{tabular}

DM=Diabetes melltus; $\mathrm{HT}=$ Hypertesion. 


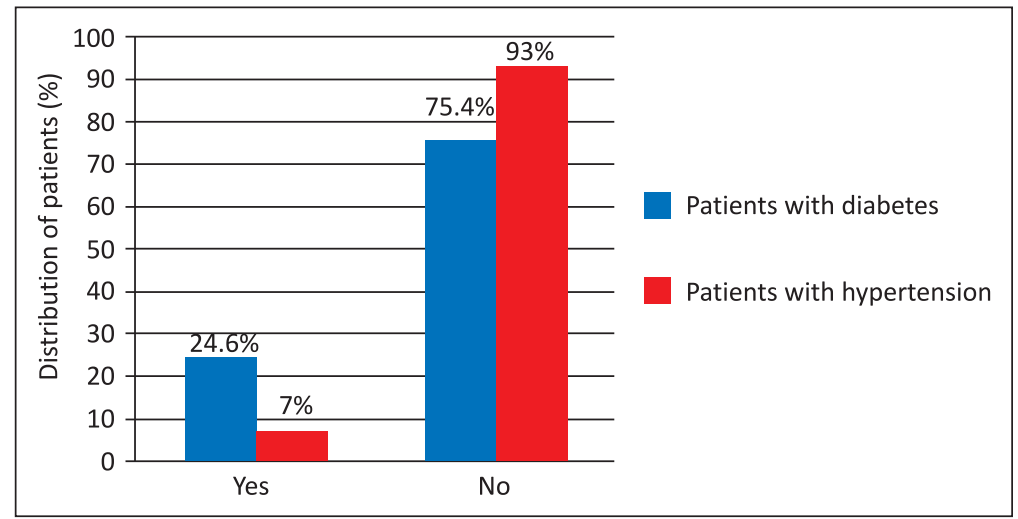

Figure 1 Distribution of patients according to their perception of disability.

Table 2 Distribution of patients by the type of hazard they were exposed to at their work place, fulfilment of labour norm, category of disability, work absenteeism, time spent on sick leave and subjective assessment of quality of life in patients with diabetes mellitus and hypertension

\begin{tabular}{|c|c|c|c|c|c|}
\hline \multirow{2}{*}{ Subject } & \multirow{2}{*}{ Offered response } & \multicolumn{2}{|l|}{ Patients } & \multirow{2}{*}{$x^{2}$} & \multirow{2}{*}{$\mathrm{p}$} \\
\hline & & $\mathrm{DM}(\mathrm{n} ; \%)$ & $\mathrm{HT}(\mathrm{n} ; \%)$ & & \\
\hline \multirow{3}{*}{ Type of damage } & Physical hazard & $16(8.4)$ & $9(9)$ & \multirow{3}{*}{24.36} & \multirow{3}{*}{0.001} \\
\hline & Chemical hazard & $8(4.2)$ & $2(2)$ & & \\
\hline & Biological hazard & $4(2.1)$ & $9(9)$ & & \\
\hline \multirow{3}{*}{ Fulfilment of labour norm } & Yes & $16(8.4)$ & $4(4)$ & \multirow{3}{*}{10.04} & \multirow{3}{*}{0.002} \\
\hline & No & $43(22.5)$ & $61(61)$ & & \\
\hline & Not working currently & $132(69.1)$ & $35(35)$ & & \\
\hline \multirow{3}{*}{ Category of disability } & Lost work ability & $13(6.8)$ & $1(1)$ & \multirow{3}{*}{0.431} & \multirow{3}{*}{0.512} \\
\hline & Partial work ability & $34(17.8)$ & $6(6)$ & & \\
\hline & No Disability & $144(75.4)$ & $93(93)$ & & \\
\hline \multirow{2}{*}{$\begin{array}{l}\text { Have you been on a sick } \\
\text { leave in the past year? }\end{array}$} & Yes & $25(42.4)$ & $19(29.2)$ & \multirow{2}{*}{2.33} & \multirow{2}{*}{0.127} \\
\hline & No & $34(57.6)$ & $46(70.8)$ & & \\
\hline \multirow{3}{*}{ Duration of sick leave } & Up to month & $14(56)$ & $10(52.6)$ & \multirow{3}{*}{1.17} & \multirow{3}{*}{0.512} \\
\hline & Up to four months & $6(24)$ & $5(26.3)$ & & \\
\hline & More than 4 months & $5(20)$ & $4(21.1)$ & & \\
\hline \multirow{3}{*}{$\begin{array}{l}\text { Subjective assessment of } \\
\text { quality of life }\end{array}$} & Good & $25(13.1)$ & $35(35)$ & \multirow{3}{*}{24.32} & \multirow{3}{*}{0.001} \\
\hline & I am satisfied & $103(53.9)$ & $51(51)$ & & \\
\hline & Bad & $63(33.0)$ & $14(14)$ & & \\
\hline \multirow{2}{*}{$\begin{array}{l}\text { Presence of anxiety and } \\
\text { stress }\end{array}$} & Yes & $154(80.6)$ & $53(53)$ & \multirow{2}{*}{24.40} & 0.001 \\
\hline & No & $37(19.4)$ & $47(47)$ & & 0.001 \\
\hline
\end{tabular}

DM=Diabetes mellitus; $\mathrm{HT}=$ Hypertension .

tients with hypertension, $93 \%$ had preserved ability to work. Table 2 shows that $8.4 \%$ of patients with diabetes mellitus, and $4 \%$ of patients with hypertension had a perception of the inability to work. The patients with diabetes mellitus were significantly more likely to experience problems in their work place than patients who were suffering from hypertension $(\chi 2=10.04, p<0.002)$. When it comes to work absenteeism (sick leave), out of 59 employed patients with diabetes mellitus, $42.4 \%$ used sick leave over the past year, compared to $28.2 \%$ of hypertension patients. However, no statistically significant 
difference in terms of work absence between patients with diabetes mellitus and hypertension was found $(\chi 2=2.33, \mathrm{p}=0.127)$ (Table $2)$. The largest number of patients with diabetes mellitus (56\%) used sick leave in the past year for up to one month, while $20 \%$ used sick leave of up to 4 months (Table 2).

Statistically significant differences in the perception of quality of own life were found between the two groups $(\chi 2=24.32, \mathrm{p}<0.001)$. More than half $(53.9 \%)$ of all patients with diabetes mellitus estimated that the quality of their daily life was satisfactory, $13.1 \%$ said that their quality of life was good and 63 (33\%) of all patients suffering from diabetes mellitus said that their quality of life was very bad. In the hypertension group, $51 \%$ of patients said that they were satisfied with their quality of life and $35 \%$ said is was good.

The majority of patients with diabetes mellitus stated that they felt anxiety daily, compared to patients with hypertension (53\%). A high statistically significant difference regarding the presence of anxiety was found between the groups $\left(\chi^{2}=24.40\right.$, $\mathrm{p}<0.001$ ) (Table 2).

Mean scores for the subscales of SF-36 for study patients are shown in Table 3. Patients with hypertension had significantly lower quality of life (QoL) scores than patients with diabetes for physical functioning, role physical, general health, social functioning and role emotional (Table 3).
Patients with diabetes mellitus were significantly more constrained in the past 4 weeks in terms of work or other activities, as a result of physical health, compared to the patients with hypertension. The difference between these two groups here is statistically highly significant $\left(\chi^{2}=29.1, p<0.01\right)$. Patients with diabetes mellitus experienced more difficulties in performing work or other activities over the past 4 weeks due to emotional problems compared to the hypertensive group $\left(\chi^{2}=14.4, \mathrm{p}=0.006\right)$. Eleven per cent of patients with diabetes mellitus and $3 \%$ of patients with hypertension were constrained to perform work or other activities "all the time".

The correlation between the QoL instrument (SF-36) and the clinical severity of diabetes mellitus is shown in Table 4 . Spearman's correlation coefficients between SF-36 and three parameters (perception of disability, productivity loss and absenteeism) ranged from 0.077 to 0.408 determining a weak relationship. The highest correlations were found between productivity loss and the bodily pain scale of SF-36 ( $\mathrm{r}=0.408$; $\mathrm{p}<0.01$ ), and between productivity loss scale and the role emotional scale of SF-36 $(\mathrm{r}=0.366 ; \mathrm{p}<0.05)$.

A significant negative correlation was observed between the perception of disability and physical functioning $(\mathrm{r}=-0.356 ; \mathrm{p}<0.05)$, social functioning $(\mathrm{r}=-0.382 ; \mathrm{p}<0.01)$ and

Table 3 SF 36 mean scores for patients with diabetes mellitus and hypertension

\begin{tabular}{llll}
\hline \multirow{2}{*}{ Variable } & \multicolumn{2}{l}{ Patients } & $\mathrm{p}$ \\
\cline { 2 - 4 } & $\mathrm{DM}(\mathrm{n}=191)$ & $\mathrm{HT}(\mathrm{n}=100)$ & 0.004 \\
\hline Physical functioning & $72.4^{* *}$ & 52.5 & 0.037 \\
Role physical & $78.3^{*}$ & 62.8 & 0.268 \\
Bodily pain & 65.1 & 58.0 & 0.026 \\
General health & $82.8^{*}$ & 67.3 & 0.562 \\
Vitality & 57.0 & 54.5 & 0.027 \\
Social functioning & $71.6^{*}$ & 64.6 & 0.008 \\
Role emotional & $75.4^{* *}$ & 60.9 & 0.236 \\
Mental health & 73.2 & 71.1 & \\
\hline
\end{tabular}

DM=Diabetes mellitus; $H T=$ Hypertension; ${ }^{*} p<0.05 ;{ }^{* *} p<0.01$. 
Table 4 Interscale correlation between SF-36 and clinical severity of disease (DM; $n=191)$

\begin{tabular}{lllllllll}
\hline Variable & PF & RP & BP & GH & VT & SF & RE & MH \\
\hline Perception of disability & $-0.356^{*}$ & 0.251 & 0.077 & 0.161 & $-0.182^{*}$ & $-0.382^{*}$ & 0.154 & -0.148 \\
Productivity loss & $-0.153^{*}$ & 0.173 & $0.408^{* *}$ & 0.168 & 0.238 & $-0.187^{*}$ & $0.366^{*}$ & -0.206 \\
Absenteeism & 0.209 & -0.147 & 0.137 & $-0.202^{*}$ & -0.170 & 0.158 & 0.115 & 0.234 \\
\hline
\end{tabular}

$\mathrm{DM}=$ Diabetes mellitus; $\mathrm{PF}=$ Physical functioning; $\mathrm{RP}=$ Role physical; $\mathrm{BP}=$ Bodily pain, $\mathrm{GH}=$ General health; $\mathrm{VT}=\mathrm{Vitality} ; \mathrm{SF}=\mathrm{Social}$ functioning $\mathrm{RE}=$ Role emotional; $\mathrm{MH}=$ Mental health; ${ }^{*} \mathrm{p}<0.05 ;{ }^{* *} \mathrm{p}<0.01$.

Table 5 Multivariable model for the Social functioning domain of the SF-36 questionnaire of patients with diabetes mellitus and hypertension $(n=291)$

\begin{tabular}{lllll}
\hline $\begin{array}{llll}\text { Socio demographic, occupational and psychological } \\
\text { characteristics of patients }\end{array}$ & $\mathrm{B}$ & \multicolumn{2}{l}{$95 \% \mathrm{Cl}$} & $\mathrm{p}$ \\
\cline { 3 - 4 } & & Lower bound & Upper bound & \\
\hline Age & -0.082 & -0.261 & 0.117 & 0.459 \\
Gender & 0.097 & -0.095 & 0.288 & 0.322 \\
Education & 0.365 & 0.082 & 0.628 & 0.011 \\
Occupation & 0.980 & 0.620 & 1.341 & $<0.001$ \\
Ability to work & 0.267 & 0.031 & 0.502 & 0.027 \\
Diabetes & 0.567 & 0.303 & 0.729 & $<0.001$ \\
Hypertension & 0.212 & -0.246 & 0.657 & 0.372 \\
Duration of disease & -0.180 & -0.368 & 0.008 & 0.060 \\
Depression & 1.042 & 0.448 & 1.614 & 0.001 \\
Anxiety & 0.986 & 0.620 & 1.341 & $<0.001$ \\
Smoking & 0.129 & -0.084 & 0.295 & 0.284 \\
Alcohol consumption & -0.096 & -0.419 & 0.291 & 0.722 \\
\hline
\end{tabular}

$B=$ coefficient for the constant.

vitality $(\mathrm{r}=-0.182 ; \mathrm{p}<0.05)$. We also found a significant negative correlation between productivity loss and social functioning scale $(\mathrm{r}=-0.187 ; \mathrm{p}<0.05)$ (Table 4$)$.

A multivariate analysis showed that the independent factors associated with the score of SF-36 were the presence of diabetes, depression and anxiety, education, occupation and ability to work. Hypertension and disease duration were not significant determinants of SF-36 score (Table 5).

\section{Discussion}

This study showed that patients with diabetes mellitus were more likely to face problems with work productivity and being constrained in terms of work and other activities. Also, diabetes mellitus patients reported a significant decline in all daily activities due to emotional and physical health problems. Besides diabetes mellitus, education, occupation, ability to work and the presence of anxiety or depression had a significant influence on their quality of life.

These findings are consistent with other studies. The systematic review by Breton et al., (9) included 23 studies investigating the impact of diabetes on ability-to-work outcomes. Studies were conducted in many countries using different study designs and involving different settings (general population or specific population of workers) and age groups. In addition, outcomes definition of productivity measures, recall periods, statistical analyses and variables used for adjustment differ considerably across those studies that assessed the same outcomes. The effects of diabetes mellitus on absenteeism, productivity loss, and early retirement 
are generally consistent across studies with high methodological quality. In the majority of studies, diabetes mellitus had a significant negative impact on the ability-to-work outcomes considered. Studies focusing on presenteeism are not considered to have low risk of bias $(2,6,8,9,18,19)$.

The number of days lost annually from work per employee that reported in the studies included with high methodological quality ranges between 5.4 and 18.1 days for employees with diabetes and between 3.4 and 8.7 for those without diabetes mellitus. Individuals with diabetes mellitus have between two and ten days absences per year more than those without diabetes mellitus. This result suggests that the associated economic burden could be high for employers. Finally, individuals with diabetes retired 0.7 years earlier compared with individuals without diabetes mellitus (9).

From the results of different studies it is evident that the working ability of the population is an extremely important issue for each country because it involves the labour force as an element of economic power, so it is not only an individual, but also a social category. The active population or labour force of a country (ages 15-65 years), according to a WHO report comprises approximately $50 \%$ to $60 \%$ of the population whose labour produces all its economic and material values, ensuring the socio-economic development of the country (20).

This study showed that diabetes mellitus has a major impact on work productivity and the early occurrence of disability in people with this illness. Due to the inability to meet requirements at the workplace, a large number of patients try to obtain a disability pension, but they are often rejected by the Commission for assessment of disability, so they continue working at the same job in spite of the difficulties they have already experienced. In Bosnia and Herzegovina and almost all countries in the Balkans, the number of applications for disability pensions is quite high (21).

In the study conducted in Montenegro (2005-2006), on a sample of the 3055 workers, who were referred for assessment of their working ability, it was found that diabetes mellitus was in third place of the overall causes of disability (45\%) (22). In the study by Šljivić et al. (23) ,which included an analysis of 9,313 individuals who were referred to the Committee for disability of Serbia for working ability assessment, it was shown that only $30.86 \%$ were categorized as invalids of the first category (equivalent to today's assessment of "the loss of working ability") $(22,23)$.

According to the results pertaining to the SF-36 quality of life questionnaire, patients with diabetes mellitus were significantly more constrained in terms of work or other activities, as a result of physical health than the other group of patients, with hypertension. This result was not unexpected since it is known that diabetes mellitus can lead to the occurrence of pain in the legs and the inability for prolonged walking or standing. Diabetes is a risk factor of the appearance of atherogenic plaques because chronic hyperglycaemia is a direct cause of the process of atherosclerosis. A high percentage of patients with diabetes mellitus stated that they had had problems in the past four weeks, at work or in other activities as a result of emotional problems such as anxiety. However, scores on SF-36 questionnaire were also determined by education, occupation, the ability to work of the patients, as well as the presence of psychological disturbances. This is consistent with studies that show that people with diabetes mellitus have a higher incidence of psychological disturbances, about one and a half times greater than the rest of the population (24).

From the literature it is known that certain psychological disorders maybe the result of not only primary psychiatric dis- 
orders, but may be the result of some metabolic disorders, such as diabetes mellitus. Quality of life in people with diabetes mellitus is substantially dependent, not only on the sphere of good metabolic control, but also on a stable psychological status and other elements of the patient's context (25). Psychological symptoms in patients with diabetes are reflected in the appearance of the burden of disease, which may be accompanied by weaker concentration, a sense of guilt and other disorders ranging from anxiety and nervousness, to burn out syndromes that occur in connection with diabetes (26).

Different studies showed that work disability is significantly higher for individuals with diabetes mellitus than for those without diabetes at all ages, and results in a significant decrease in earnings $(27,28)$. Our study showed that there is a significant correlation between productivity to work, work absence or perception of disability and patients' functional status. There is the evidence that diabetes mellitus affects patients, employers, and society not only by reducing employment but also by contributing to work loss and health-related work limitations for those who remain employed. Its effects on employment and work productivity are likely to become more pressing for society (29). Even after controlling for other factors presumed to be relevant to the decision to work, such as other chronic health conditions and job characteristics, it was found that diabetes reduced the absolute likelihood of working. The economic burden associated with diabetes mellitus is likely to increase as diabetes mellitus becomes more prevalent. Since diabetes mellitus is a progressive disease, one may speculate that the occurrence or progression of diabetes mellitus complications may lead to functional impairment or limitations to performance and these individuals to stop working. Therefore, the prevention of both diabetes mellitus and its complications through medication, diet, and exercise, is likely to yield economic benefits, in addition to preserving the health status and quality of life of individuals who are at risk for developing or who already have diabetes (29-31).

This study does however, have some limitations. This was a cross-sectional study so it cannot determine cause and effect, but it can identify potential associations. Secondly, we are aware that the sample size achieved in the study was lower than that calculated and hence this affects/limits generalizations from the data to a wider population. Larger and more longitudinal data are needed to provide a better assessment of the causes and effects of diabetes on ability-to-work outcomes.

Nevertheless, the results of this study indicate that there is a substantial impact on the ability to work and patients' HRQoL associated with diabetes. In fact, they suggest that employers, insurers, and decision makers should pay attention to ability to work because of diabetes mellitus and could help employers better manage services overseen by various managers of human resources and employee benefits programs, such as paid sick days, medical insurance, and education or intervention programs.

\section{Conclusion}

Diabetes mellitus appears to reduce an individual's ability to work. Patients with diabetes mellitus experienced more difficulties in performing work or other activities due to emotional problems compared to the hypertensive group. The majority of patients with diabetes mellitus stated that they feel anxiety daily, compared to patients with hypertension (53\%). There is a need for setting up diabetes prevention programs and to develop and implement effective targeted intervention to help workers better manage their disease. Otherwise this diabetes mellitus-related burden could worsen in the 
working-age population. Efficient employer-implemented intervention programs to improve the physical health and well-being of their workers with diabetes could be a good strategy for controlling productivityrelated costs.

Authors' contributions: Conception and design: VKS, MR; Acquisition, analysis and interpretation of data: MR, BNJ, VRJ; Drafting the article VKS, MR; Revising it critically for important intellectual content: BNJ, VRJ.

Conflict of interest: The authors declare that they have no conflict of interest.

\section{References}

1. Reif N. Principles of professional expertise in pension and disability insurance scheme [In Croatian]. In: Čapeta R, Reif N, Ribarić M, Rismondo M, editors. Work ability and disability. Zagreb: University in Zagreb - Faculty of medicine; 1987. p. 57-76.

2. Alivinia SM, Burdorf A. Unemployement and retirement and ill-health: a cross-sectional analyses across European countries. Int Arch Occup Environ Health. 2008;82(1):39-45.

3. Herquelot, Gueguen A, Bonenfant S, Dry-Spira R. Impact of diabetes on work cessation: data from the GAZEL cohort study. Diabetes Care. 2011;34:1344-9.

4. Latif E. The impact of diabetes on employment in Canada. Health Econ. 2009;18:577-89.

5. daCosta DiBonaventura M, Cappelleri JC, Joshi, AV. A longitudinal assessment of painful diabetic peripheral neuropathyon health status, productivity, and health care utilization and cost. Pain Med. 2011;12:118-26.

6. Cawley J, Rizzo JA, Haas K. The association of diabetes with jog abseneesim costs among obese and morbidly obese worker. J Occuo Environ Med. 2008;50:527-34.

7. Holden L, Scuffham PA, Hilton MF, Ware RS, Vecchio N, Whiteford HA. Which health conditions impact on productivity in working Australians? J Occup Environ Med. 2011;53:253-7.

8. Vamos EP, Mucsi I, Keszei A, Kopp MS, Novak M. Comorbid depression in associated with increased healthcare utilization and lost productivity in persons with diabetes: a large nationally representative Hungarian population survey. Psychosom Med. 2009;71:501-7.
9. Breton MC, Guénette L, Amiche MA, Kayibanda JF, Grégoire JP, Moisan J. Burden of diabetes on the ability to work: a systematic review. Diabetes Care. 2013;36(3):740-9.

10. Pavlović M, Marić-Milić B, Janičić L. Prevalence of diabetes mellitus in emloyees with disability [In Serbian]. Medicinski zapisi. 2009;32(Suppl 1):S135-6.

11. osha.europa.eu [homepage on the internet]. Bilbao: European Agency for Safety and Health at Work, Inc.; c1998-2014 [updated 2014 October 29; cited 2014 November 1]. Available from: https://osha.europa.eu/en/.

12. Wild S, Roglic G, Green A, Sicree R, King H. Global prevalence of diabetes: estimatesfor the year 2000 and projections for 2030. Diabetes Care. 2004;27:1047-53.

13. Centers for Disease Control and and Prevention. National diabetes fact sheet: national estimates and general information on diabetes and prediabetes in the - united States, 2011. Atlanta, GA, U.S. Department of Health and Human Services, Centers for Disease Control and Prevention, 2011.

14. Public Health Institute of Republic of Srpska. Analysis of population health in Republic of Srpska. Banja Luka: RM Print; 2012.

15. Ware JE, Snow KK, Kosinski M, Gandek B. SF-36 Health Survey Manual and Interpretation Guide. Boston, Ma: New England Medical Center, The Health Institute; 1993.

16. Ware JE. SF-36 Health Survey update. Spine. 2000;25:(24)3130-9.

17. www.proqolid.org [homepage on the internet]. Lyon: ProQuolid Patient-Reported Outcome and Quality of Life Instruments Database SF-36 Health Survey Serbian version. Inc.;c2001-14 [updated 2014 October 26; cited 2014 November 1] Available from http://www.proqolid.org/.

18. Mayfield JA, Deb P, Whitecotton L. Work disability and diabetes. Diabetes Care 1999;22:1105-9.

19. Tunceli K, Bradley CJ, Nerenz D, Williams LK, Pladevall M, Elston Lafata J. The impact of diabetes on employment and work productivity. Diabetes Care 2005;28:2662-7.

20. WHO Declaration on Occupational Health for All. Geneva: World Health organisation; 1996.

21. Raggi P, Deffer O, Shaw LJ. In: Fonseca V, editor. Clinical Diabetes. New Orleans: Saunders-Elsevier; 2006. p.225.

22. Janičić L, Marić-Milić B, Pavlović M. The most common causes of disability as resulat of cardivascular diseases [In Serbian]. Medicinski zapisi. 2009;47(Suppl 1):S154-5. 
23. Šljivić M. Evaluation of permanent disability for work in patients with hypertension [In Serbian]. [specialist scientific research]. Faculty of medicine in Belgrade: Belgrade; 1997.

24. Egede LE, Zheng D. Independent factors associated with major depressive disorder in a national sample. Diabetes Care. 2003;26:104-11.

25. Low LL, Tong SF, Low WY. Mixed feelings about the diagnosis of type 2 diabetes mellitus: a consequence of adjusting to health related quality of life. Coll Antropol. 2014;38(1):11-20.

26. Ruston A, Smith A, Fernando B. Diabetes in the workplace - diabetic's perceptions and experiences of managing their disease at work: a qualitative study. BMC Public Health. 2013;13:386.

27. Mayfield JA, Deb P, Whitecotton L. Work disability and diabetes. Diabetes Care. 1999;22(7):1105-9.
28. Espelt A, Borrell C, Roskam AJ, et al. Socioeconomic inequalities in diabetes mellitus across $\mathrm{Eu}-$ rope at the beginning of the 21 st century. Diabetologia 2008;51:1971-9.

29. Musich SA, Schultz AB, Burton WN, Edington DW. Overview of disease management approaches: implications for corporate sponsored programs. Dis Manag Health Outcomes. 2004;12:299-326.

30. American Diabetes Association: Economic costs of diabetes in the U.S. in 2002. Diabetes Care. 2003;26:917-32.

31. Vijan S, Hayward RA, Langa KM: The impact of diabetes on workforce participation: results from a national household sample. Health Serv Res. 2004;39:1653-69. 